DR DAVID O'KEEFE (Orcid ID : 0000-0002-1666-3445)

DR HUI YIN LIM (Orcid ID : 0000-0003-2455-3155)

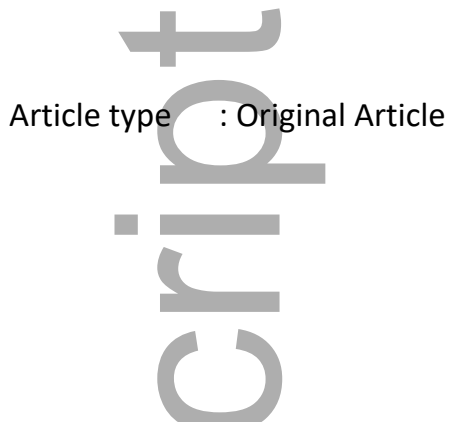

Manuscript pages: 31

Figures: 2

\title{
Assessing maternal clotting function with novel global coagulation assays: a prospective pilot study
}

Running title: GCAs in pregnancy

Dr David O'Keefe BSc MD ${ }^{a, d}$, Dr Hui Yin Lim MBBS (Hons) BMedSc FRACP FRCPA, Dr Jonathan Tham BSc MD ${ }^{a, d}$, Dr Prahlad Ho MBBS (Hons) PhD BMedSc FRACP FRCPA ${ }^{b, c}, A / P r o f$ Lisa Hui MBBS PhD FRANZCOG CMFM DDU a,d,e

aDepartment of Obstetrics and Gynaecology, Faculty of Medicine, Dentistry \& Health Sciences, The University of Melbourne

${ }^{b}$ Department of Haematology, Northern Health

'Northern Pathology Victoria, Northern Health

${ }^{d}$ Department of Obstetrics \& Gynaecology, Northern Health

eDepartment of Perinatal Medicine, Mercy Hospital for Women

\section{Corresponding author:}

A/Prof Lisa Hui

Department of Obstetrics \& Gynaecology

This is the author manuscript accepted for publication and has undergone full peer review but has not been through the copyediting, typesetting, pagination and proofreading process, which may lead to differences between this version and the Version of Record. Please cite this article as doi: 10.1111/IJLH.13389

This article is protected by copyright. All rights reserved 
Northern Health

185 Cooper Street

EPPING VIC 3076 Australia

E: lisa.hui@unimelb.edu.au

Word count: 3507

Table count: 3

Figure count: 2

Keywords: pregnancy, venous thromboembolism, global coagulation assay, thromboelastography, obesity

Abstract

Introduction: Women are at higher risk of venous thromboembolism (VTE) during pregnancy and the puerperium. Global coagulation assays (GCAs) including thromboelastography (TEG), thrombin generation using the calibrated automated thrombogram (CAT) and fibrin generation using the overall haemostatic potential assay (OHP) provide a more comprehensive assessment of the coagulation process than conventional coagulation assays. We aimed to evaluate the ability of these GCAs to analyse the coagulability amongst pregnant women of varying VTE risk profile.

Methods: Women undergoing term elective caesarean delivery provided a single pre-delivery blood sample for conventional and novel coagulation testing (TEG, CAT and OHP). Data from 47 healthy non-pregnant women aged 18-45 years were used as controls.

This article is protected by copyright. All rights reserved 
Results: Sixty women with term singleton pregnancies were included. Samples from pregnant women were hypercoagulable on most GCA parameters compared to non-pregnant controls, demonstrating increased maximum amplitude (clot strength) ( 71.5 vs $60.6 \mathrm{~mm}, P<0.001)$ on whole blood TEG as well as increased endogenous thrombin potential (1895.22 vs $1399.33 \mathrm{nM}$.min, $P<0.001$ ) and overall coagulation potential (fibrin generation) (57.58 vs 36.21 units, $P<0.001$ ) on platelet-poor plasma. Pregnant women with booking BMI $\geq 30 \mathrm{~kg} / \mathrm{m}^{2} \mathrm{had}$ significantly higher maximum amplitude compared to pregnant women of normal BMI $\left(18.5-25 \mathrm{~kg} / \mathrm{m}^{2}\right)(73.2$ vs $66.1 \mathrm{~mm}, P<0.001)$.

Conclusions: GCAs reliably detect the physiological hypercoagulability of pregnancy. Thromboelastography in particular appears to correlate with obesity in the pregnant population. GCAs may be potential adjuncts to risk factor-based criteria to guide VTE thromboprophylaxis during pregnancy and the puerperium.

Keywords: pregnancy, venous thromboembolism, global coagulation assay, thromboelastography, obesity
Abbreviations
APTT, activated thromboplastin time; BMI, body mass index; CAT, calibrated automated thrombogram; $\mathrm{Cl}$, confidence interval; ETP, endogenous thrombin potential; GCA(s), global coagulation assay(s); INR, international normalised ratio; LMWH, low molecular weight heparin; MA, maximum amplitude; OCP, overall coagulation potential; OFP, overall fibrinolytic potential; OHP, overall haemostatic potential assay / overall haemostatic potential; RCOG, Royal College of Obstetricians \& Gynaecologists; ROTEM, rotational thromboelastometry; TEG, thromboelastography; VTE, venous thromboembolism. 


\section{INTRODUCTION}

Venous thromboembolism (VTE) is a leading cause of maternal morbidity and mortality in developed countries, accounting for 9.2-14\% of maternal deaths in the United States, United Kingdom and Australia ${ }^{1-3}$. Currently, the key pharmacological strategy in managing VTE risk in pregnancy and the puerperium is the use of low molecular weight heparin (LMWH), with some guidelines recommending up to $85 \%$ of women receive postpartum thromboprophylaxis after caesarean delivery ${ }^{4}$. Antenatal and postnatal VTE risk assessment relies on clinical risk factor-based stratification, drawn from casecontrol studies and consensus opinion. A Cochrane review examining VTE prophylaxis in pregnancy and the puerperium concluded there is insufficient data to guide the routine use of pharmacological VTE prophylaxis in this context ${ }^{5}$. As a result of the limited quality of evidence, recommendations for pharmacological VTE prophylaxis vary widely, carrying with this additional risk of clotting or bleeding ${ }^{6}$. With an increasing prevalence of common risk factors such as obesity and maternal age, further research to refine risk stratification strategies with laboratory testing is warranted.

Standard coagulation assays such as the prothrombin time and activated partial thromboplastin time (APTT) only measure the time to the start of clot formation or $5 \%$ of thrombin generation and are unable to detect the physiologically hypercoagulable state of pregnancy and postpartum ${ }^{7,8}$. Newer global coagulation assays (GCAs) such as thromboelastography, thrombin generation and overall haemostatic potential assay, on the other hand, measure the characteristics of total clot formation as well as endproducts of the coagulation cascade ${ }^{8}$. Changes in the elastic properties of whole blood during clot formation, propagation and dissolution can be measured with thromboelastography (TEG) and rotational thromboelastometry (ROTEM). Thrombin is a key protein in the coagulation process and thrombin generation measured using the calibrated automated thrombogram (CAT) has previously been shown to predict nonpregnant patients at increased risk of VTE recurrence ${ }^{9}$. Fibrinolysis is less well studied 
but previous small studies have observed that hypercoagulable patients have impaired fibrinolysis ${ }^{10}$ as measured using the overall haemostatic potential assay (OHP). Current data on GCAs to study the hypercoagulability of pregnancy are often limited by small samples sizes and studies do not evaluate the use of more than one GCA at a time ${ }^{11}$. By providing a more comprehensive assessment of the haemostatic profile, these GCAs may provide additional insight into the pathophysiology of hypercoagulability in the pregnant population and potentially assist VTE risk assessment as well as guide individualised thromboprophylaxis ${ }^{11-13}$.

The overall aim of this study was to evaluate the hypercoagulability of pregnancy using three GCAs, baseline haematology, biochemical parameters and comprehensive clinical history. Our first objective was to compare TEG, CAT and OHP results in pregnant women to non-pregnant healthy women of childbearing age. Our second objective was to examine the relationship between independent clinical risk factors for VTE and GCA parameters. We hypothesised that pregnant women at increased clinical risk of VTE due to either higher overall VTE risk score or body mass index (BMI) $>30$ would have more hypercoagulable GCA parameters than pregnant women at lower clinical risk.

\section{MATERIALS AND METHODS}

\section{Study design}

This was a prospective pilot study of pregnant women with term singleton pregnancies recruited between February 2018 and April 2019 from The Northern Hospital, a level 5 metropolitan maternity centre in Victoria, Australia, that births approximately 3600 infants per annum. Exclusion criteria were: non-English speaking; $<18$ years; unable to provide written informed consent; pregnancy $<37$ gestational weeks; multiple pregnancy; and fetal death. All participants were recruited prior to term elective caesarean section except for one participant who was recruited prior to induction of labour. Demographic data was collected including age, BMI at booking and term, country of birth, gravida, parity and smoking status. Booking BMI was collected from 
the woman's first recorded antenatal appointment, while BMI at term was collected from the woman's most recent antenatal appointment beyond 37 weeks' gestation. A medical, obstetric and family history was also recorded. Women were specifically asked about a personal history of diabetes, thyroid disease, previous VTE and varicose veins; current medications including insulin, thyroxine, anticoagulants and aspirin; and family history of VTE, cardiovascular disease, blood disorders and diabetes. Indications for caesarean delivery were recorded. Delivery and birth outcomes (primary blood loss, newborn weight and sex, Apgar scores and admissions to special care nursery) were collected after delivery. Each participant's risk of VTE was assessed at the time of blood collection using the Royal College of Obstetricians \& Gynaecologists (RCOG) Green-top Guideline 37a based on antenatal clinical risk factors and taking into account their imminent elective caesarean delivery and increase in parity by one (see Table S1 for risk factor scoring) ${ }^{14}$. Additional postpartum risk factors were not included in scoring for this study. According to the RCOG guideline, women with a score of 3 or more can be considered at sufficient risk to be prescribed pharmacological thromboprophylaxis from 28 weeks' gestation, while for postpartum women that threshold is a score of 2 .

Data from the healthy non-pregnant comparator group $(n=47)$ were obtained from a previously reported cohort at The Northern Hospital ${ }^{15}$. Women aged 18-45 with no known cardiovascular disease risk factors such as diabetes mellitus, hypertension, hyperlipidaemia and current smoking, no active malignancy and not on anticoagulants were included. Data on BMI was not available for our healthy non-pregnant comparator group.

\section{Laboratory methods}

Blood samples were collected by venepuncture or at venous cannulation prior to caesarean delivery or induction of labour. $25-30 \mathrm{~mL}$ of blood was drawn to fill six $3.2 \%$ sodium citrate tubes, one ethylenediaminetetraacetic acid tube and one serumseparating tube. Standard testing including full blood examination, liver function tests, 
urea, electrolytes and creatinine, coagulation profile (fibrinogen, international normalised ratio (INR), APTT) and D-dimer were performed. One citrate tube was used for TEG within 4 hours of collection. Four citrate tubes were used to prepare plateletpoor plasma within 2 hours of collection by double centrifugation at $2500 \times \mathrm{g}$ for 10 minutes each at room temperature, then stored at $-80^{\circ} \mathrm{C}$ for subsequent batch analysis with CAT and OHP.

Thromboelastography (TEG)

TEG analyses the viscoelastic properties of whole blood during clot formation, propagation and dissolution through measuring the progressive resistance of a clot in an oscillating plastic cuvette relative to a central pin. Samples were tested with the TEG5000 Thromboelastograph Haemostasis Analyzer system (Haemonetics, Braintree, MA, USA) ${ }^{16}$ pre-warmed to $37^{\circ} \mathrm{C} .1 \mathrm{~mL}$ of whole citrated blood was activated with $40 \mu \mathrm{L}$ of kaolin. A $340 \mu \mathrm{L}$ aliquot of kaolin-activated blood was pipetted into a $37^{\circ} \mathrm{C}$ cuvette with $20 \mu \mathrm{L}$ of $0.2 \mathrm{M}$ calcium chloride for analysis. The following parameters (seen in Figure 1) were assessed: $\mathrm{R}$ value (time to clot formation, minutes); $\mathrm{K}$ value (time to achieve clot strength of $20 \mathrm{~mm}$, minutes); alpha-angle (rate of clot formation, ${ }^{\circ}$ ); maximum amplitude (MA) (maximum clot strength, $\mathrm{mm}$ ); and LY30 (percentage of clot lysis 30 minutes after MA is achieved, \%).

Thrombin generation with calibrated automated thrombography (CAT) CAT determines the concentration of thrombin generated in a clot over time by measurement of a thrombin-sensitive fluorogenic substrate, which is consumed as thrombin is generated in platelet-poor plasma. A calibrator is simultaneously used to correct for the "inner filter effect" which confounds thrombin generation calculation. Samples were tested with a Fluoroskan Ascent fluorometer (Diagnostica Stago, Parsippany, NJ, USA) at $37^{\circ} \mathrm{C}$ as per manufacturer guidelines. Thrombinoscope ${ }^{\circledR}$ software outputted the following parameters: lag time (time to thrombin generation, minutes); endogenous thrombin potential (ETP, the amount of thrombin generated, 
$\mathrm{nM} / \mathrm{min}$ ); thrombin peak (maximum concentration of thrombin, $\mathrm{nM}$ ); and velocity index (rate of thrombin generation, $\mathrm{nM} / \mathrm{min}$ ).

Fibrin generation with overall haemostatic potential assay (OHP) OHP produces a fibrin-aggregation curve as repeated spectrophotometric measurements are made at $37^{\circ} \mathrm{C}$ of a platelet-poor plasma sample undergoing fibrin generation and fibrinolysis ${ }^{17}$. Each sample was combined with exogenous thrombin alone (which provides an area under the curve representing fibrin generation as the overall coagulation potential (OCP, units), as well as exogenous thrombin with tissuetype plasminogen activator (tPA) (which provides an area under the curve representing response to tPA as the overall haemostatic potential (OHP, units). The difference between the OCP and OHP reflects the overall fibrinolytic potential (OFP, \%). The FLUOstar ${ }^{\circledR}$ Optima (BMG Labtech) plate reader was used. All samples were performed in triplicates and the average derived.

\section{Statistical analysis}

Data was analysed using IBM ${ }^{\circledR}$ SPSS Version 25.0 (SPSS Inc., Chicago, IL, USA). Continuous variables were assessed for normality using the Shapiro Wilk test. Univariate comparison of pregnant with non-pregnant samples involved independent samples t-test or Mann-Whitney $\mathrm{U}$ test where appropriate. Within the pregnant cohort, analysis of variance (ANOVA) and Kruskal-Wallis tests were used to test for differences across BMI categories where appropriate. Where applicable, multivariable analysis with a generalised linear model was used with a backwards stepwise regression technique. Pearson's and Spearman's tests were used where appropriate to determine correlations between demographic and clinical data, baseline blood test results and GCA results. Statistical significance was defined at $P<0.05$.

\section{Ethical approval}


This study was approved by the Austin Health Human Research Ethics Committee, Melbourne, Victoria (HREC/17/Austin329 and AH04977). All women provided written informed consent for participation.

\section{RESULTS}

Demographics, clinical characteristics and baseline blood tests

Sixty women with singleton pregnancies were included in the study. Demographic and clinical data are summarised in Table 1 . The mean ages of the pregnant and nonpregnant groups were 31.8 and 30.2 years respectively $(P=0.194)$. One pregnant participant was on antenatal anticoagulation (enoxaparin) for previous unprovoked VTE, however this was ceased 48 hours prior to sample collection. Four (3.7\%) women had a family history of VTE in a first degree relative with no known thrombophilia.

Results of baseline blood tests are summarised in Table S2. Results were significantly different between pregnant and non-pregnant groups consistent with the known physiological changes of pregnancy ( $P$-values listed in Table S2). All but one pregnant woman had a D-dimer level above $500 \mathrm{mg} / \mathrm{L} \mathrm{FEU,} \mathrm{with} \mathrm{a} \mathrm{median} \mathrm{of} 1580 \mathrm{mg} / \mathrm{L} \mathrm{FEU} \mathrm{in}$ the pregnant group.

\section{[Insert Table 1]}

\section{Global coagulation assay results}

Comparison of pregnant cohort with non-pregnant cohort

Results of TEG, CAT and OHP are summarised in Table 2 and Figure 1. All GCA parameters were significantly different between pregnant and non-pregnant groups ( $P$-values listed in Table 2$)$. In the pregnant group, all GCA parameters except lag time reflected hypercoagulability. In particular, the pregnant group showed markedly increased maximum amplitude (clot strength) (71.5 vs $60.6 \mathrm{~mm}, P<0.001)$, ETP and peak thrombin (1895.22 vs 1399.33 nM.min, $P<0.001$ and 320.91 vs $240.01 n M$, 
$P<0.001$ respectively) as well as increased fibrin generation (OCP) (57.58 vs 36.21 units, $P<0.001)$ and reduced overall fibrinolytic potential $(76.25$ vs $82.07 \%, P<0.001)$.

[Insert Table 2] [Insert Figure 1]

Correlations with baseline blood tests

Among pregnant women, there were significant correlations between fibrinogen and fibrin generation parameters: $\mathrm{OCP}\left(\mathrm{r}_{\mathrm{s}}=0.873, P<0.001\right), \operatorname{OHP}\left(\mathrm{r}_{\mathrm{s}}=0.854, P<0.001\right)$ and $\operatorname{OFP}\left(r_{s}=-0.726, P<0.001\right)$ as well as TEG parameters: MA $\left(r_{s}=0.323, P=0.013\right)$ and alphaangle $\left(r_{s}=0.322, P=0.013\right)$. There were no correlations between fibrinogen and $D$ dimer, ETP nor LY30. There were also no correlations between fibrin generation parameters and D-dimer.

Analysis of pregnant cohort by BMI and weight category Results of TEG, CAT and OHP in women of normal booking BMI $\left(18.5-24.9 \mathrm{~kg} / \mathrm{m}^{2}\right)$ compared to obese women are summarised in Table 3. At booking, overweight (25.0$\left.29.9 \mathrm{~kg} / \mathrm{m}^{2}\right)$, obese $\left(30.0-34.9 \mathrm{~kg} / \mathrm{m}^{2}\right)$ and very obese $\left(\geq 35 \mathrm{~kg} / \mathrm{m}^{2}\right)$ women had a higher MA compared to women of normal BMI $(P<0.001)$ (Figure 2). Statistical significance of these comparisons was maintained when controlling for age, parity, smoking status and diabetes ( $B=7.309,95 \%$ confidence interval $(C l) ; 4.26$ to $10.36, P<0.001)$. At booking, very obese women had a higher OCP compared to women of normal BMI (62.63 vs 54.51 units, $P=0.026$ ). At term, very obese women had a higher MA compared to those of normal BMI (73.1 vs $68.0 \mathrm{~mm}, P=0.030)$. No significant differences in CAT or other OHP parameters were seen between weight categories. There were significant correlations between booking $B M I$ and $M A(r=0.397, P=0.002)$ and term $B M I$ and MA $(r=0.297, P=0.022)$. There were no significant correlations between BMI and CAT or OHP parameters.

[Insert Table 3] [Insert Figure 2] 


\section{Analysis of pregnant cohort by clinical VTE risk}

Of the seven women who theoretically would have qualified for antenatal thromboprophylaxis from 28 weeks' gestation under the RCOG Green-top Guideline $37 a^{14}$, five were obese at booking and only one had been prescribed antenatal thromboprophylaxis. Forty-two women (70\%) theoretically would have qualified for postpartum thromboprophylaxis taking into account their imminent elective caesarean delivery and increase in parity by one. There were no differences in GCA parameters between women who qualified for antenatal or postnatal thromboprophylaxis under RCOG guidelines and those who did not. The most common postpartum risk factors were elective caesarean delivery, obesity, parity $\geq 3$ and age $>35$ ( $n=59$ (98.3\%), n=25 (41.7\%), $n=22$ (36.7\%) and $n=18$ (30\%) respectively). Of all GCA parameters, only thrombin peak correlated with RCOG antenatal and postpartum raw VTE risk scores $\left(r_{s}=0.267, P=0.039\right.$ and $r_{s}=0.324, P=0.012$ respectively).

There were no differences in any GCA parameters between women with and without a history of previous VTE ( $n=3$ and $n=57$ respectively). There were no correlations between age and any GCA parameters other than thrombin peak $\left(r_{s}=0.257, P=0.048\right)$. OCP and OHP were negatively correlated with parity $\left(r_{s}=-0.296, P=0.023\right.$ and $r_{s}=-0.336$, $P=0.009$ respectively) while OFP was positively correlated with parity $\left(r_{s}=0.312\right.$, $P=0.016)$. Women with any form of diabetes mellitus did not have significant differences in any GCA parameters compared to non-diabetic women, other than a significantly decreased lag time (means: 3.00 vs $3.28 \mathrm{~min}, P=0.028$ ).

\section{Clinical outcomes}

All women had live births and other birth outcome data have been summarised in Table 1. Two women (3.3\%) had an intra-operative blood loss estimate of $1000 \mathrm{~mL}$, however the only difference in GCA parameter was a lower thrombin peak compared to those who did not (medians: 248.40 vs $319.03 \mathrm{nM}, P=0.028$ ). Three women were prescribed postnatal thromboprophylaxis for six weeks, based on The Northern Hospital postpartum VTE risk assessment guidelines ${ }^{18}$. No women experienced a 
postpartum VTE prior to discharge and none had any medical record of presenting to The Northern Hospital with VTE during the six-week puerperium.

\section{DISCUSSION}

This prospective observational study is the only study of its kind to simultaneously investigate three different GCA in pregnant women, providing a comprehensive profile of coagulation. Our results provide a comprehensive analysis of the hypercoagulability of pregnancy and detected a correlation between GCA parameters and BMI among the pregnant cohort.

Compared to non-pregnant women, all three GCAs showed hypercoagulability in term pregnant women, a difference not apparent on routine INR and APTT testing. TEG demonstrated overall hypercoagulability in term pregnancy consistent with previous literature, including earlier and more rapid clot formation, stronger clot strength, and slower clot breakdown ${ }^{19-23}$. Our CAT findings are similar to those which studied women at any point in third trimester, demonstrating an increased thrombin peak and ETP compared to early pregnancy or non-pregnant women ${ }^{24-27}$, suggesting an upregulation of thrombin generation in pregnancy. We note that lag time was slightly more prolonged in the pregnant population although the absolute difference to nonpregnant women was minimal (3.3 vs $2.9 \mathrm{~min}$ ). The OHP assay demonstrated increased fibrin generation (OCP) in pregnancy and reduced fibrinolysis (OFP), consistent with previous studies ${ }^{10,28}$. Of interest, in our study D-dimer levels did not correlate with any fibrin generation parameters using OHP, despite being a fibrin degradation product, highlighting a current knowledge gap in the complexity of the fibrinolytic pathway, which warrants further investigation.

$\mathrm{BMI}$ and weight category were key risk factors of interest in the study, given the global obesity epidemic and its well-recognised ability to drive increased thrombotic disorders through all three arms of Virchow's triad ${ }^{29}$. The finding of increased clot strength in overweight and obese pregnant women compared to those of normal BMI 
is a novel finding and contributes to our understanding of the mechanisms of VTE in obese pregnant women. Other studies examining obesity in pregnancy had variable results. Morgan et $\mathrm{al}^{30}$ found no difference in any TEG parameters amongst obese and non-obese women $>36$ weeks' gestation, nor did Lee at $a^{31}$ find any association between BMI and ROTEM parameters in pregnant women at term. However, Sharma et $\mathrm{al}^{32}$ found a trend of increasing clot strength with BMI in pregnancy, though this did not meet statistical significance. Whilst not significant, a trend of increasing ETP and OCP in obese pregnant women compared to those of normal BMI may also suggest a role of obesity in VTE risk. Some studies have suggested that obesity-driven chronic inflammation involves key modulators of prothrombotic pathways and impaired fibrinolysis has been reported to be a major effector mechanism of thrombosis ${ }^{33}$. Whilst we were able to demonstrate hypofibrinolysis in the pregnant cohort compared to the non-pregnant group, with decreased LY3O using TEG and decreased OFP using $\mathrm{OHP}$, there were no differences in these parameters between obese women at term and those of normal BMI. Our analysis of BMI was limited to the pregnant cohort, as data for BMI in the non-pregnant comparator group was not available.

No significant differences in GCA parameters between the three women at highest clinical risk of VTE (those with prior VTE) were seen compared to the rest of the pregnant cohort, nor were there any differences between those who theoretically qualified for antenatal or postnatal thromboprophylaxis and those who did not based on the RCOG Green-top Guideline $37 \mathrm{a}^{14}$. However, thrombin peak appeared to correlate to raw VTE risk scores. We acknowledge that no definitive conclusion can be drawn as the statistical power of our comparisons of GCA parameters between these groups was limited by unequal numbers in each group. It is important to note, however, that clinical risk assessments incorporate a wide range of factors. GCAs only measure the 'hypercoagulability' arm of Virchow's triad and it is likely that the other two components, endothelial dysfunction and stasis, also contribute significantly to the overall hypercoagulable state in pregnancy ${ }^{30,34}$. Even with a larger sample size, a previous study found no difference in CAT parameters between women at high clinical 
risk of VTE compared to normal pregnancies ${ }^{35}$. These findings highlight the complexity of coagulation pathways and suggest that multimodal risk algorithms incorporating both clinical risk factors and biomarkers of coagulation such as GCAs should be investigated in future studies.

Results of standard coagulation profile tests (INR and APTT) confirmed that they are unhelpful in discerning hypercoagulability in pregnancy. D-dimer and fibrinogen levels were increased above non-pregnant reference range to a similar extent previously described in pregnancy ${ }^{36}$. That $98.3 \%$ of women had a raised D-dimer level and none experienced a postpartum VTE confirms that D-dimer level on its own is not appropriate for the general risk assessment of pregnancy-associated VTE.

A key strength of this study lies in its simultaneous evaluation of three different GCAs alongside baseline haematology and biochemical parameters. We were able to see significant hypercoagulable changes when comparing pregnant and non-pregnant women, despite a relatively small sample size. The comprehensive collection of clinical data allowed thorough assessment of antenatal and postpartum VTE risk using RCOG guidelines. The timeframe of the study also allowed us to follow up the medical records of women six weeks postpartum to ensure none re-presented to the maternity centre with VTE.

One of our study limitations was that BMI was not available for our non-pregnant cohort, and we were therefore unable to adjust for this factor when comparing the non-pregnant group to the obstetric cohort. As our recruitment was largely from elective caesarean theatre lists, we acknowledge that our pregnant cohort may not represent the general obstetric population as caesarean births are known to be associated with higher maternal age, parity and $\mathrm{BMI}^{37,38}$. Our pregnant cohort also had a relative high rate of gestational diabetes mellitus (GDM) (31.7\%) when compared with our institution's general obstetric population $(14.7 \%)^{37}$. This was likely due to the timing of study recruitment at the beginning of the morning operating lists, when women with GDM are preferentially scheduled for their caesarean births. 
While this study represents one of the largest cohorts of pregnant women at term for this field of study, larger prospective studies are still needed to establish reference values for GCAs in pregnancy. Reference ranges for healthy pregnancy and postpartum have been established for TEG and ROTEM ${ }^{13,39}$, however this remains an area of need for CAT and OHP as studies are limited by small sample sizes ${ }^{10,26}$. Further clinical trials would then be required to validate their accuracy before incorporating them into routine use. Only then would a large-scale prospective study be able to validate a risk assessment tool incorporating GCAs.

Several other challenges which must be addressed before GCAs could be considered for implementation into routine VTE risk scores. CAT and OHP, still in their infancy, can be labour and time intensive with inter-operator variability and lack of inter-laboratory standardisation ${ }^{8}$. Ensuring standardised protocols for all GCAs in regard to collection, processing, storage and substrates used would be of benefit to minimise variability in future studies.

\section{CONCLUSION}

This pilot study, to our knowledge, is the first of its kind to simultaneously evaluate TEG, CAT and OHP in pregnant women. Unlike currently validated coagulation assays, each GCA was able to consistently detect the physiological hypercoagulability of pregnancy previously described in the literature. Our results suggest that GCAs hold promise for understanding the mechanisms underlying the relationship between BMI and VTE risk during pregnancy, particularly with TEG. Further large clinical studies in pregnant women are warranted to evaluate the role of GCAs in the prediction of pregnancy-associated VTE.

\section{Acknowledgements}

This article is protected by copyright. All rights reserved 
We would like to thank the anaesthetic, maternity and operating theatre staff who supported participant recruitment and sample collection, as well as the laboratory staff for routine testing of samples.

\section{Conflicts of interest}

The authors have no conflicts of interest to declare.

\section{Funding}

This work was funded by a 2017 Northern Health Small Research Grant, courtesy of the Northern Health Foundation, Epping VIC Australia, and in-kind support from Northern Pathology Victoria.

\section{Data availability statement}

The data that support the findings of this study are available from the corresponding author upon reasonable request.

\section{REFERENCES}

1. Australian Government. Maternal deaths in Australia. Australian Institute of Health and Welfare. https://www.aihw.gov.au/reports/mothersbabies/maternal-deaths-in-australia. Updated November 26, 2019. Accessed July 9, 2020.

2. Knight M, Bunch K, Tuffnell D et al on behalf of MBRRACE-UK. Saving lives, improving mothers' care: lessons learned to inform maternity care from the UK and Ireland confidential enquiries into maternal deaths and morbidity 2014-16. Oxford: National Perinatal Epidemiology Unit, University of Oxford; 2018. https://www.npeu.ox.ac.uk/downloads/files/mbrrace-uk/reports/MBRRACEUK\%20Maternal\%20Report\%202018\%20-\%20Web\%20Version.pdf. Accessed February 7, 2019. 
3. Creanga AA, Syverson C, Seed K, Callaghan WM. Pregnancy-related mortality in the United States, 2011-2013. Obstet Gynecol. 2017; 130:366-73.

4. Palmerola KL, D'Alton ME, Brock CO, Friedman AM. A comparison of recommendations for pharmacologic thromboembolism prophylaxis after caesarean delivery from three major guidelines. BJOG. 2016;123:2157-62.

5. Bain E, Wilson A, Tooher R, Gates S, Davis L, Middleton P. Prophylaxis for venous thromboembolic disease in pregnancy and the early postnatal period. Cochrane Database Syst Rev. 2014;(2):CD001689. doi:10.1002/14651858.CD001689.pub3.

6. Kotaska A. Postpartum venous thromboembolism prophylaxis may cause more harm than benefit: a critical analysis of international guidelines through an evidence-based lens. BJOG. 2018;125:1109-16.

7. Lipets EN, Ataullakhanov FI. Global assays of hemostasis in the diagnostics of hypercoagulation and evaluation of thrombosis risk. Thromb J. 2015;13(1):4.

8. Lim HY, O’Malley C, Donnan G, Nandurkar H, Ho P. A review of global coagulation assays - Is there a role in thrombosis risk prediction? Thromb Res. 2019;179:45-55.

9. Tripodi A, Legnani C, Chantarangkul V, Cosmi B, Palareti G, Mannucci PM. High thrombin generation measured in the presence of thrombomodulin is associated with an increased risk of recurrent venous thromboembolism. J Thromb Haemost. 2008;6:1327-33.

10. Curnow JL, Morel-Kopp M-C, Roddie C, Aboud M, Ward CM. Reduced fibrinolysis and increased fibrin generation can be detected in hypercoagulable patients using the overall hemostatic potential assay. J Thromb Haemost. 2007;5:528-34.

11. Ataullakhanov FI, Koltsova EM, Balandina AN, Serebriyskiy II, Vuimo TA, Panteleev MA. Classic and global hemostasis testing in pregnancy and during pregnancy complications. Semin Thromb Hemost. 2016;42(7):696-716.

12. Othman M, Han K, Elbatarny M, Abdul-Kadir R. The use of viscoelastic hemostatic tests in pregnancy and puerperium: review of the current evidence 
- communication from the Women's Health SSC of the ISTH. J Thromb Haemost. 2018;17:1184-1189.

13. Amgalan A, Allen T, Othman M, Ahmadzia H. Systematic review of viscoelastic testing (TEG/ROTEM) in obstetrics and recommendations from the women's SSC of the ISTH. J Thromb Haemost. 2020;18:1813-1838.

14. Nelson-Piercy C, MacCallum P, Mackillop L. Reducing the risk of thrombosis and embolism during pregnancy and the puerperium. Green-top guideline no. 73a. London: Royal College of Obstetricians \& Gynaecologists; 2015. https://www.rcog.org.uk/globalassets/documents/guidelines/gtg37a.pdf?UNLID=408523912017688380. Accessed September 7, 2018.

15. Ho P, Ng C, Rigano J, Tacey M, Smith C, Donnan G, Nandurkar H. Significant age, race and gender differences in global coagulation assay parameters in the normal population. Thromb Res. 2017;154:80-3.

16. Haemoscope Corporation. TEG ${ }^{\circledR} 5000$ Thromboelastograph ${ }^{\circledR}$ Hemostasis System: TEG Analytical Software (TAS) Version 4.2.3. 2007. https://studylib.net/doc/18643089/pn06-510-teg-5000-user-manual. Accessed October 4, 2020.

17. Antovic A. The overall haemostasis potential: a laboratory tool for the investigation of global haemostasis. Semin Thromb Hemost. 2010;36(7):772-9.

18. Northern Health. VTE risk assessment for post-partum women. Document number FNH367870. Updated September 13, 2018. Accessed September 13, 2018

19. Sharma SK, Philip J, Wiley J. Thromboelastographic changes in healthy parturients and postpartum women. Anesth Analg. 1997;85:94-8.

20. Della Rocca G, Dogareschi T, Cecconet T et al. Coagulation assessment in normal pregnancy: thrombelastography with citrated non activated samples. Minerva Anestesiol. 2012;78(12):1357-64.

21. Karlsson O, Sporrong T, Hillarp A, Jeppsson A, Hellgren M. Prospective longitudinal study of thromboelastography and standard hemostatic laboratory 
tests in healthy women during normal pregnancy. Anesth Analg. 2012;115(4):890-8.

22. Macafee B, Campbell JP, Ashpole K et al. Reference ranges for thromboelastography $\left(\mathrm{TEG}^{\circledR}\right)$ and traditional coagulation tests in term parturients undergoing caesarean section under spinal anaesthesia. Anaesthesia. 2012;67(7):741-7.

23. Antony KM, Mansouri R, Arndt M et al. Establishing thromboelastography with platelet-function analyzer reference ranges and other measures in healthy term pregnant women. Am J Perinatol. 2015;32(6):545-54.

24. Rosenkranz A, Hiden M, Leschnik B et al. Calibrated automated thrombin generation in normal uncomplicated pregnancy. Thromb Haemost. 2008;99(2):331-7.

25. Dargaud Y, Hierso S, Rugeri L et al. Endogenous thrombin potential, prothrombin fragment $1+2$ and D-dimers during pregnancy. Thromb Haemost. 2010;103(2):469-71.

26. Macey MG, Bevan S, Alam S et al. Platelet activation and endogenous thrombin potential in pre-eclampsia. Thromb Res. 2010;125:e76-e81.

27. McLean KC, Bernstein IM, Brummel-Ziedins KE. Tissue factor-dependent thrombin generation across pregnancy. Am J Obstet Gynecol. 2012;207:135.e16.

28. He S, Antovic A, Blombäck M. A simple and rapid laboratory method for determination of haemostasis potential in plasma: II. Modifications for use in routine laboratories and research work. Thromb Res. 2001;103:355-61.

29. Morgan ES, Wilson E, Watkins T, Gao F, Hunt BJ. Maternal obesity and venous thromboembolism. Int J Obstet Anesth. 2012;21(3):253-63.

30. Morgan ES, Wilson E, Melody T et al. An observational study of haemostatic changes, leptin and soluble endoglin during pregnancy in women with different BMIs. Blood Coagul Fibrinolysis. 2017;28(1):50-5. 
31. Lee J, Eley VA, Wyssusek KH et al. The influence of obesity on coagulation in healthy term pregnancy as assessed by rotational thromboelastometry. Aust $N$ Z J Ostet Gynaecol. 2020. doi: 10.1111/ajo.13141

32. Sharma S, Uprichard J, Moretti A, Boyce H, Szydlo R, Stocks G. Use of thromboelastography to assess the combined role of pregnancy and obesity on coagulation: a prospective study. Int J Obstet Anesth. 2013;22(2):113-8.

33. Blokhin IO, Lentz SR. Mechanisms of thrombosis in obesity. Curr Opin Hematol. 2013;20(5):437-44.

34. Hunt BJ. The effect of BMI on haemostasis: Implications for thrombosis in women's health. Thromb Res. 2017;151:S53-S5

35. Joly BS, Sudrié-Arnaud B, Barbay V, Borg J-Y, Duchez VLC. Thrombin generation test as a marker for high risk venous thrombosis pregnancies. J Thromb Thombolysis. 2018;45:114-21.

36. Epiney $M$, Boehlen $F$, Boulvain $M$ et al. D-dimer levels during delivery and the postpartum. J Thromb Haemost. 2005;3(2):268.71.

37. Pratt A, Howat P, Hui L. Maternal and perinatal outcomes for women with body mass index $\geq 50 \mathrm{~kg} / \mathrm{m}^{2}$ in a non-tertiary hospital setting. Aust N Z J Ostet Gynaecol. 2020;60(3):361-8.

38. Australian Commission on Safety and Quality in Health Care. Australian Atlas of Healthcare Variation 2017: 3.4 Caesarean section. Sydney: Australian Commission on Safety and Quality in Health Care; 2017. https://www.safetyandquality.gov.au/sites/default/files/migrated/3.4Caesarean-section.pdf - page 3. Accessed October 4, 2020.

39. Yang J, Yang H, Tang A et al. Trimester-specific reference intervals for kaolinactivated thromboelastography (TEG) in healthy Chinese pregnant women. Thromb Res. 2019;184:81-85.

Table 1: Demographic and clinical data of pregnant cohort and birth outcomes

\begin{tabular}{|c|c|}
\hline Variable & Pregnant women $(n=60)$ \\
\hline Age, years (mean $\pm S D$ ) & $31.8 \pm 4.1$ \\
\hline
\end{tabular}




\begin{tabular}{|c|c|}
\hline Gestation, weeks (median (IQR)) & $39(1)$ \\
\hline Parity (median) & 1 \\
\hline - $\quad$ Nulliparous (\%) & $7(11.7)$ \\
\hline - Multiparous (\%) & $53(88.3)$ \\
\hline Medical history & +-- \\
\hline - $\quad B M I \geq 30 \mathrm{~kg} / \mathrm{m}^{2}$ at booking $\mathrm{n},(\%)$ & $25(41.7)$ \\
\hline - GDM managed with insulin $n,(\%)$ & $12(20.0)$ \\
\hline - $\quad$ GDM managed with diet control $n,(\%)$ & $7(11.7)$ \\
\hline - $\quad$ Any current diabetes $n,(\%)$ & $20(33.3)$ \\
\hline - $\quad$ Previous VTE n, (\%) & $3(5.0)$ \\
\hline Mode of delivery & --- \\
\hline - $\quad$ Caesarean delivery (\%) & $59(98.3)$ \\
\hline - $\quad$ Normal vaginal delivery (\%) & $1(1.7)$ \\
\hline Smoking status & --- \\
\hline - $\quad$ Never smoked (\%) & $43(71.7)$ \\
\hline - $\quad$ Current smoker (\%) & $6(10.0)$ \\
\hline - Ex-smoker (\%) & $11(18.3)$ \\
\hline Body mass index at booking $\left(\mathrm{kg} / \mathrm{m}^{2} ;\right.$ median (IQR)) & $28.5(7.0)$ \\
\hline Body mass index at booking $\left(\mathrm{kg} / \mathrm{m}^{2}\right)$ & --- \\
\hline - $\quad 18.5-24.9 \mathrm{~kg} / \mathrm{m}^{2}(\%)$ & $13(21.7)$ \\
\hline$-\quad 25-29.9 \mathrm{~kg} / \mathrm{m}^{2}(\%)$ & $22(36.7)$ \\
\hline - $\quad 30-34.9 \mathrm{~kg} / \mathrm{m}^{2}(\%)$ & $17(28.3)$ \\
\hline$-\quad \geq 35 \mathrm{~kg} / \mathrm{m}^{2}(\%)$ & $8(13.3)$ \\
\hline Body mass index at term $\left(\mathrm{kg} / \mathrm{m}^{2} ;\right.$ median (IQR)) & $32.0(6.0)$ \\
\hline Body mass index at term $\left(\mathrm{kg} / \mathrm{m}^{2}\right)$ & --- \\
\hline$-18.5-24.9(\%)$ & $3(5.0)$ \\
\hline - $\quad 25-29.9(\%)$ & $15(25.0)$ \\
\hline$-\quad 30-34.9(\%)$ & $24(40.0)$ \\
\hline$-\quad \geq 35(\%)$ & $18(30.0)$ \\
\hline Country of birth & --- \\
\hline $\begin{array}{ll} & \text { Australia (\%) }\end{array}$ & $27(45.0)$ \\
\hline - $\quad$ India (\%) & $15(25.0)$ \\
\hline
\end{tabular}

This article is protected by copyright. All rights reserved 


\begin{tabular}{|c|c|}
\hline - $\quad$ Other $^{\mathrm{a}}(\%)$ & $18(30.0)$ \\
\hline Indication for caesarean delivery $(n=59)$ & --- \\
\hline - Previous caesarean delivery (\%) & $42(70.0)$ \\
\hline - Breech or transverse lie (\%) & $7(11.7)$ \\
\hline - $\quad$ Placenta previa (\%) & $3(5.0)$ \\
\hline $\begin{array}{l}\text { - Patient choice or previous complicated vaginal } \\
\text { delivery (\%) }\end{array}$ & $6(10.0)$ \\
\hline - $\quad$ Other $(\%)$ & $1(1.7)$ \\
\hline Primary blood loss, mL (median (IQR)) & $325(150)$ \\
\hline Newborn weight, grams (mean \pm SD) & $3426.17 \pm 508.94$ \\
\hline Newborn outcomes & --- \\
\hline - $\quad$ Male (\%) & $29(48.3)$ \\
\hline - $\quad$ Female (\%) & $31(51.7)$ \\
\hline Number immediately admitted to special care nursery (\%) & $8(13.3)$ \\
\hline Number with APGAR $<7$ at 5 mins (\%) & $0(0.0)$ \\
\hline
\end{tabular}

Abbreviations: $\mathrm{BMI}$, body mass index; GDM, gestational diabetes mellitus; IQR, interquartile range; SD, standard deviation; VTE, venous thromboembolism

a Other countries of birth: New Zealand, Iran, Nepal, Ghana, Greece, South Africa, Vietnam and Philippines

Table 2: GCA results in pregnant vs non-pregnant women

\begin{tabular}{|c|c|c|c|c|c|c|}
\hline Assay & \multirow[t]{2}{*}{ Variable } & \multicolumn{2}{|r|}{ Pregnant } & \multicolumn{2}{|c|}{ Non-pregnant* } & \multirow{2}{*}{$\frac{P \text {-value }}{0.013}$} \\
\hline \multirow{5}{*}{ TEG } & & \multirow{4}{*}{$n=59$} & $5.8 \pm 1.6$ & \multirow{5}{*}{$n=37$} & $6.9 \pm 2.4$ & \\
\hline & K value & & $1.4(0.5)$ & & $2.2(0.9)$ & $<0.001$ \\
\hline & Alpha angle & & $65.8 \pm 6.5$ & & $54.1 \pm 11.3$ & $<0.001$ \\
\hline & Maximum amplitude & & $71.5 \pm 5.1$ & & $60.6 \pm 6.6$ & $<0.001$ \\
\hline & Lysis 30 & $n=58$ & $0.0(0.1)$ & & $0.6(2.1)$ & $<0.001$ \\
\hline \multirow[b]{2}{*}{ CAT } & Lag time & \multirow[b]{2}{*}{$n=60$} & $3.28 \pm 0.61$ & \multirow[b]{2}{*}{$n=47$} & $2.89 \pm 0.60$ & 0.001 \\
\hline & $\begin{array}{l}\text { Endogenous thrombin } \\
\text { potential }\end{array}$ & & $\begin{array}{c}1895.22 \pm \\
380.32\end{array}$ & & $\begin{array}{c}1399.33 \pm \\
286.13\end{array}$ & $<0.001$ \\
\hline
\end{tabular}

This article is protected by copyright. All rights reserved 


\begin{tabular}{|c|c|c|c|c|c|c|}
\hline \multicolumn{2}{|r|}{ Thrombin peak } & & $\begin{array}{c}320.91 \pm \\
64.31\end{array}$ & & $\begin{array}{c}240.01 \pm \\
71.63\end{array}$ & $<0.001$ \\
\hline & Velocity index & & $\begin{array}{c}110.70 \pm \\
38.24\end{array}$ & & $\begin{array}{c}83.97 \pm \\
40.28\end{array}$ & 0.001 \\
\hline \multirow{3}{*}{ OHP } & $\begin{array}{l}\text { Overall coagulation } \\
\text { potential }\end{array}$ & & $\begin{array}{c}57.58 \pm \\
10.53\end{array}$ & \multirow{3}{*}{$n=44$} & $36.21 \pm 7.71$ & $<0.001$ \\
\hline & $\begin{array}{l}\text { Overall haemostatic } \\
\text { potential }\end{array}$ & $n=59$ & $13.44(6.41)$ & & $6.65(3.28)$ & $<0.001$ \\
\hline & $\begin{array}{l}\text { Overall fibrinolytic } \\
\text { potential }\end{array}$ & & 76.25 (6.64) & & $82.07(5.48)$ & $<0.001$ \\
\hline
\end{tabular}

Normally distributed variables are reported as mean \pm SD. Non-normally distributed variables are reported as median (IQR).

Statistical significance of normally distributed variables determined with independent samples t-test; statistical significance of non-normally distributed variables determined with MannWhitney $U$ test.

Abbreviations: CAT, calibrated automated thrombogram; OHP, overall haemostatic potential assay; TEG, thromboelastography.

* = non-pregnant population defined as non-pregnant women aged 18-45 with no cardiovascular disease risk factors, no active malignancy and not on anticoagulants

Table 3: GCA results in pregnant women of normal vs obese BMI at booking

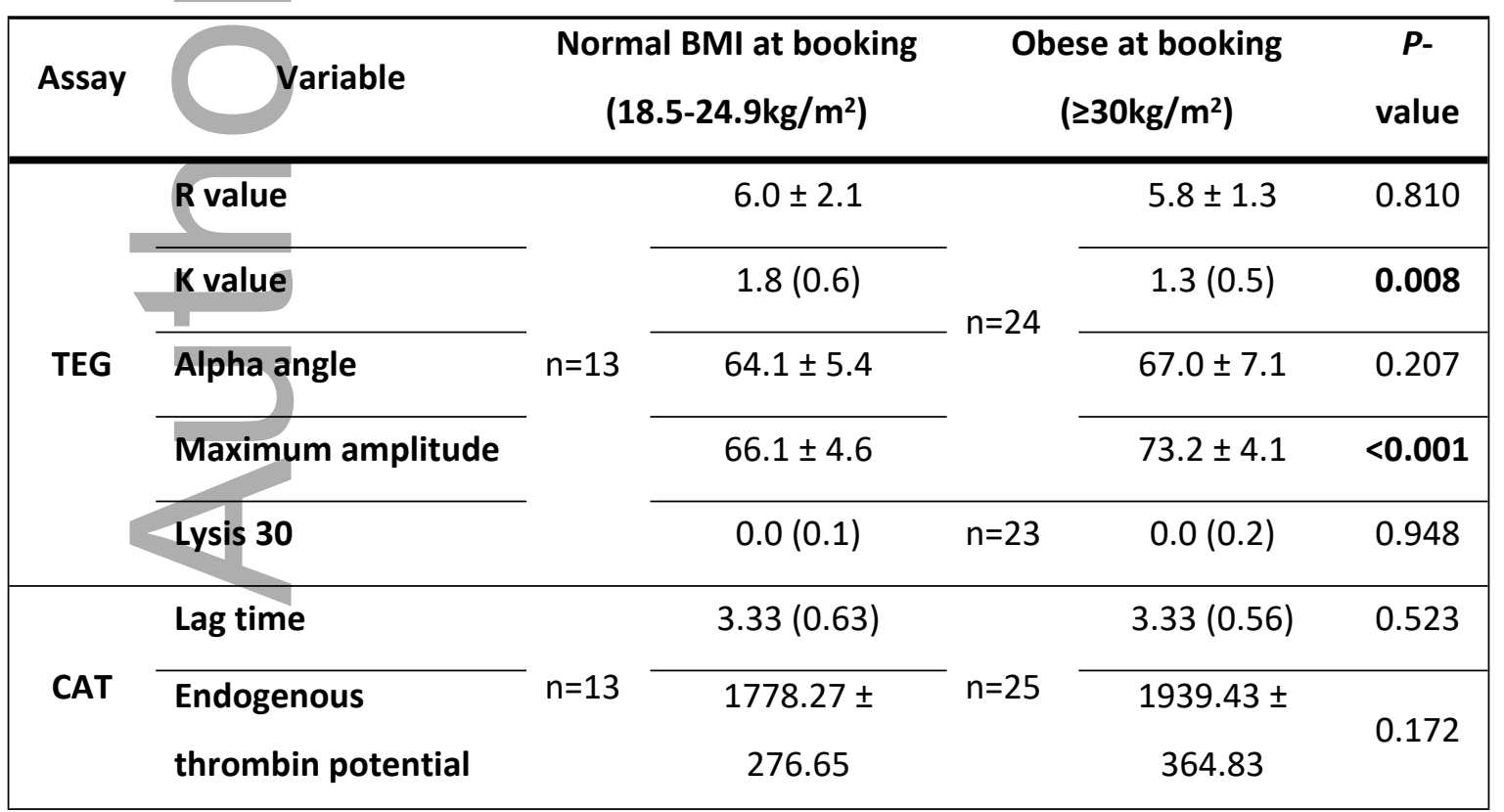




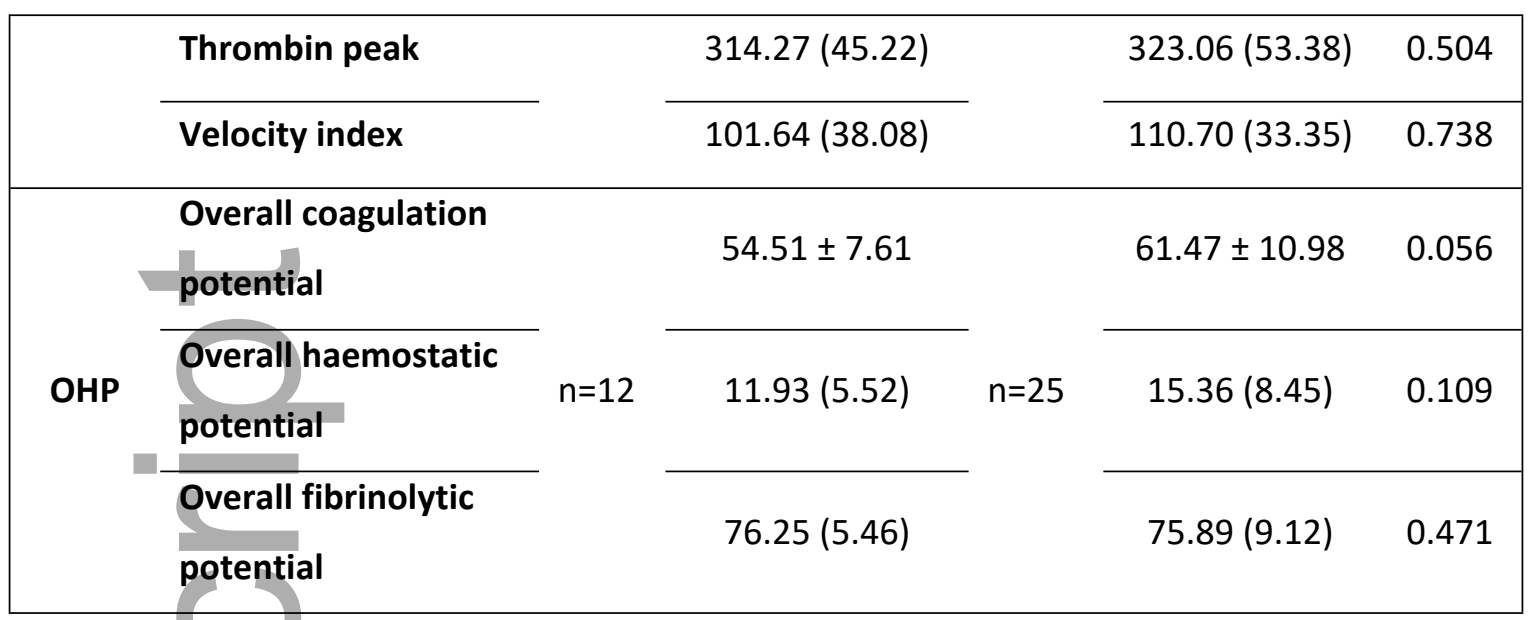

Normally distributed variables are reported as mean \pm SD. Non-normally distributed variables are reported as median (IQR).

Statistical significance of normally distributed variables determined with independent samples t-test; statistical significance of non-normally distributed variables determined with MannWhitney $U$ test.

Abbreviations: CAT, calibrated automated thrombogram; OHP, overall haemostatic potential assay; TEG, thromboelastography.

\section{Figure legends}

Figure 1: Graphical output of TEG (A), CAT (B) and OHP (C) results in pregnant and nonpregnant groups.

Figure 2: Box plot of maximum amplitude (using TEG) according to booking BMI category among pregnant women. Box plots represent the range of data from $25^{\text {th }}$ to $75^{\text {th }}$ percentile; the bar in the middle of each box plot represents the median value. The whiskers extending from each box plot represent the range of values obtained excluding outliers. ${ }^{*}=P<0.001$ compared with normal BMI $\left(18.5-24.9 \mathrm{~kg} / \mathrm{m}^{2}\right) .^{\circ}=$ outlier (1.5 $x$ the IQR).

\section{Supporting information}

Table S1: Risk factors for VTE in pregnancy and the puerperium, and risk assessment for VTE, adapted from 2015 Royal College of Obstetricians \& Gynaecologists Green-top Guidelines ${ }^{14}$. 
Table S2: Baseline blood and coagulation profile results in pregnant vs non-pregnant women

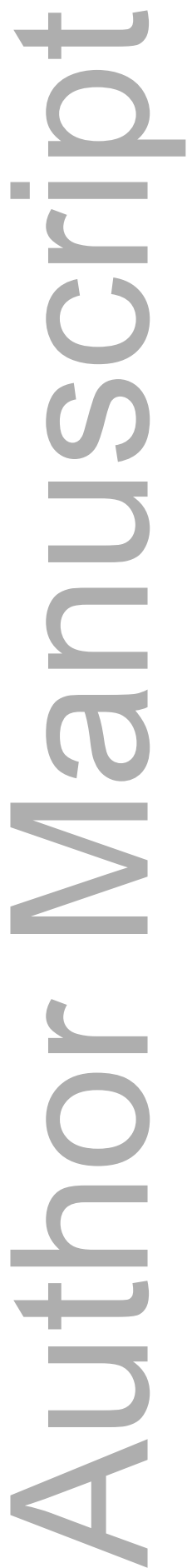

This article is protected by copyright. All rights reserved 


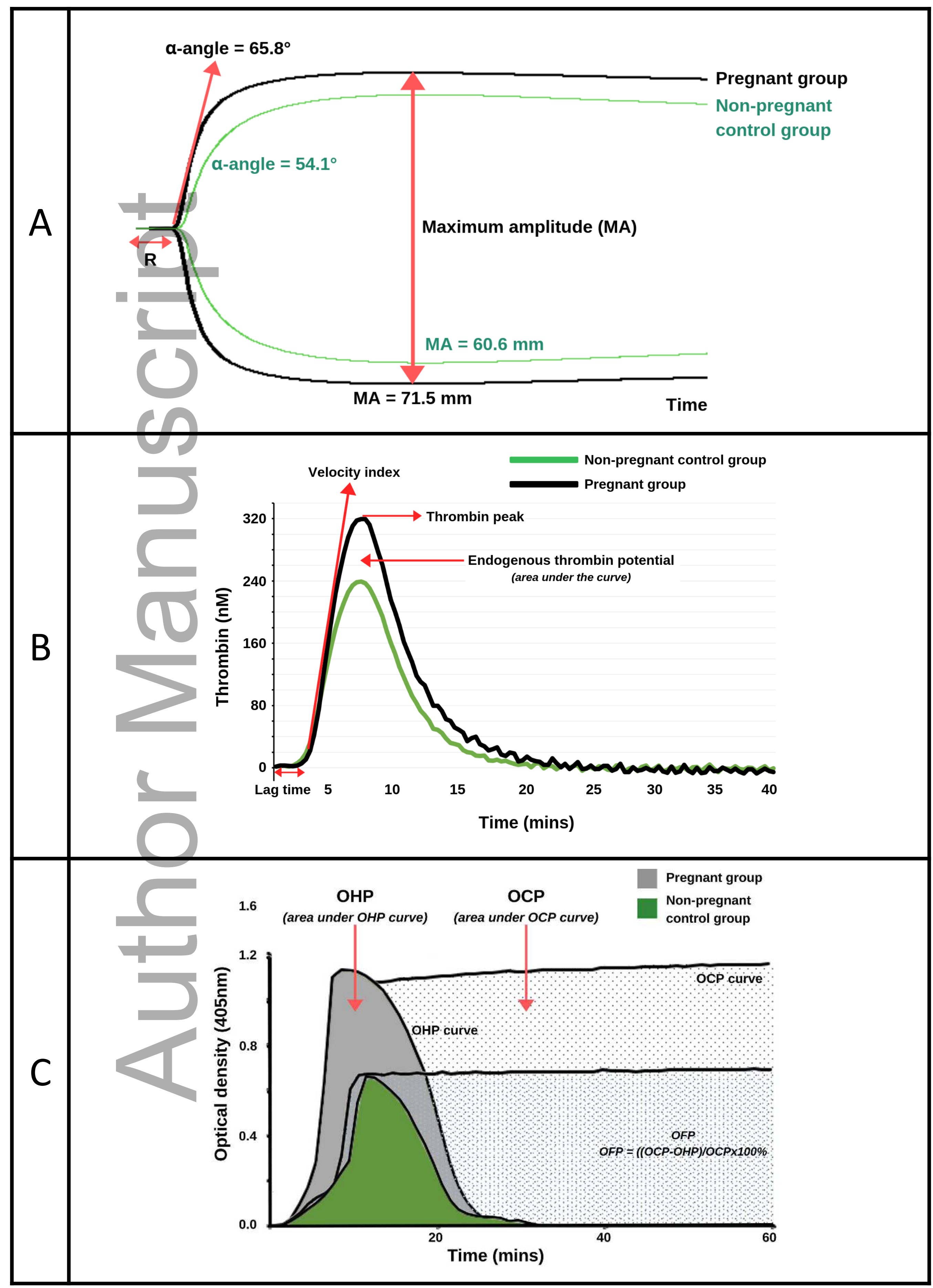



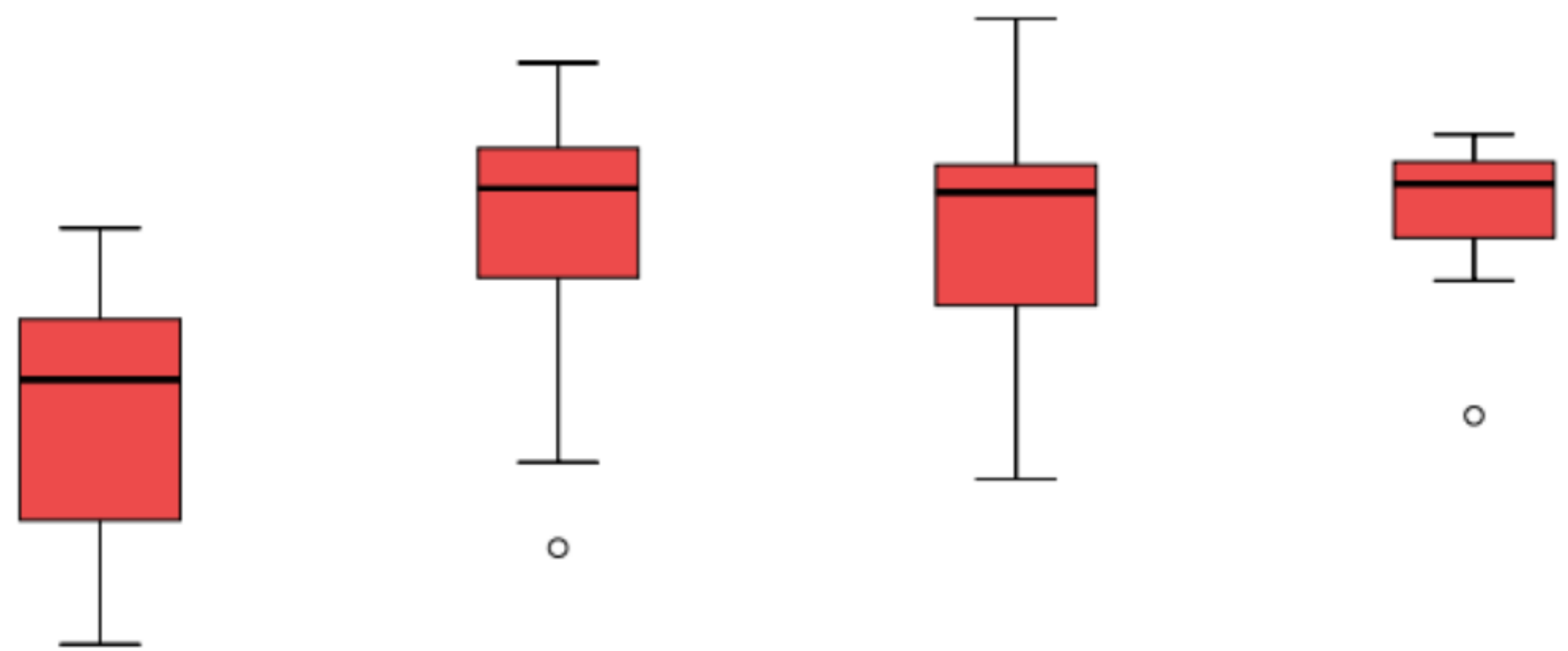

60

$\circ$

50

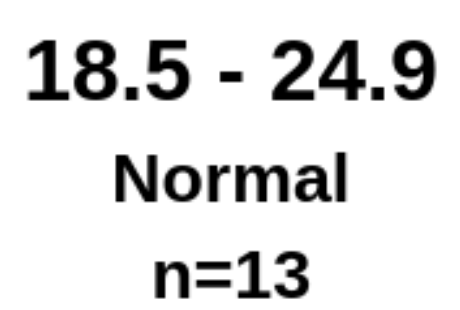
25.0 - 29.9
Overweight
$\mathrm{n}=22$
$30.0-34.9$
Obese
$\mathrm{n}=17$

$\geqslant 35.0$

Very obese

$n=8$ 


\section{University Library}

\section{- $\mathrm{M}$ IIN E R VA A gateway to Melbourne's research publications}

Minerva Access is the Institutional Repository of The University of Melbourne

Author/s:

O'Keefe, D;Lim, HY;Tham, J;Ho, P;Hui, L

Title:

Assessing maternal clotting function with novel global coagulation assays: A prospective pilot study

Date:

2020-11-10

Citation:

O'Keefe, D., Lim, H. Y., Tham, J., Ho, P. \& Hui, L. (2020). Assessing maternal clotting function with novel global coagulation assays: A prospective pilot study. INTERNATIONAL JOURNAL OF LABORATORY HEMATOLOGY, 43 (3), pp.458-467. https://doi.org/10.1111/ ijlh. 13389.

Persistent Link:

http://hdl.handle.net/11343/276597 